\title{
Teatro e pesquisa etnográfica da práxis como métodos para a mudança: reflexões de um projeto de cooperação teuto-brasileiro*
}

\author{
Bettina Völter**
}

\section{Introdução}

O projeto de teatro teuto-brasileiro “Luz que Anda”, sobre o qual irei expor aqui, surgiu no final de 2004 a partir da iniciativa de três mulheres. “Luz que Anda” significa algo como "luz em movimento". O foco do projeto está localizado em um distrito do estado de Minas Gerais. Já participam do projeto desde então pessoas com origens nacionais, étnicas e sociais bastante distintas. Assim que a luz já se espalhou espontaneamente. O obje-

* Texto original em alemão traduzido por Hermílio Santos. A primeira parte do artigo foi publicado originalmente em Miethe, Ingrid; Fischer, Wolfram; Giebeler, Cornelia; Goblirsch, Martina e Riemann, Gerhard (org.): "Rekonstruktion und Intervention”: Interdisziplinäre Beiträge zur rekonstruktiven Sozialarbeitsforschung. (Rekonstruktive Forschung in der Sozialen Arbeit, Band 4). Opladen \& Farmington Hills: Verlag Barbara Budrich, 2007: 149-160.

** Doutora em sociologia pela Technische Universität Berlin e professora da Alice Salomon Hochschule Berlin (www.asfh-berlin.de).

\begin{tabular}{l|l|l|l|l|l|} 
Civitas & Porto Alegre & v. 7 & n. 2 & jul.-dez. 2007 & p. 48-64 \\
\hline
\end{tabular}


tivo da iniciativa é, com os recursos do teatro, ampliar as potencialidades, a criatividade, bem como o horizonte de todos aqueles envolvidos, mas principalmente construir uma oferta sócio-cultural para as crianças, jovens e adultos do distrito, fomentar o intercâmbio transcultural e apoiar o engajamento civil. Nesse contexto, é especialmente importante para o distrito alcançar maior visibilidade em nível regional, assim como a possibilidade de participação e influência em assuntos que dizem respeito à população, como o problema do lixo, o transporte de crianças para a escola, localizada a $15 \mathrm{~km}$ de distância, o fornecimento de água potável, a arborização do distrito, a ampliação de um centro de convivência para iniciativas sócioculturais.

Luz que Anda trabalha com os recursos do teatro participativo e do jogo de representação, além de métodos de orientação etnográfica e sócioespacial da pesquisa da práxis ou pesquisa-ação. Este artigo trata de como se combinam prática e conceitos, nesta experiência. Ao final, discuto as expectativas, as áreas de influência recíproca, as imprecisões e as questões éticas que tal projeto transcultural de cooperação suscita. E como tais reflexões podem se constituir em parte do trabalho conjunto.

Porém, para uma melhor compreensão farei uma breve descrição histórica do projeto e da situação social da localidade. Há vinte anos a pedagoga brasileira Geralda Araújo e eu trabalhamos juntas durante cinco meses em uma creche de uma favela em Belo Horizonte. Mais tarde Geralda passou dez anos na Alemanha e retornou depois ao Brasil com sua família formada na Alemanha. Na primavera de 2004 procurei por um parceiro brasileiro para que pudesse construir um projeto social em cooperação entre uma faculdade alemã e uma iniciativa brasileira. Geralda Araújo se dispôs a trabalhar junto e formulou a idéia de realizar um projeto para crianças e adolescentes em Serra Negra. Serra Negra é uma pequena localidade com cerca de 130 famílias, próximo a Divinópolis, onde ela reside hoje. Seus pais migraram desse distrito para Belo Horizonte há 50 anos. A família sempre manteve estreito contato com Serra Negra, lá possuem parentes e os visitam com freqüência. Geralda Araújo é bastante conhecida e considerada na localidade, e o desenvolvimento do distrito é um desejo seu. Seu avô é tido na localidade como um sábio curandeiro, que já ajudou muitas pessoas. 
Serra Negra é habitada em parte por imigrantes do nordeste de Minas. A outra parte da população mora na localidade há muitas gerações. Uma particularidade do local é que durante os fins-de-semana, ou em determinadas festas, parte daqueles moradores que migraram para grandes cidades voltam para visitar; alguns deles possuem casas nas quais moram nesses períodos. A maior parte dos habitantes foi recrutada por uma enorme granja industrial. Uma outra parte trabalha como peões ou empregados domésticos para os poucos fazendeiros. Na localidade existem como oferta de cultura e de lazer a igreja, com cultos regulares ministrados por um Padre, que é responsável por vinte e três paróquias. Na maioria das vezes os cultos são ministrados por laicos. Existem também três grandes grupos de reza organizados em torno de famílias e um grupo de dança de congado. Além disso, têm as festas com visitas de fora (como o Reinado), às vezes tem a visita de um circo. E no distrito funcionam quatro bares. A maioria da população deseja mudar a situação de vida. Mas muitos dizem que perderam a esperança de que alguma coisa vá mudar.

Geralda Araújo queria então organizar oportunidades para as crianças do lugar e apoiar o desenvolvimento da localidade. Tive a idéia de, junto com ela, iniciar um projeto de teatro inspirado no modelo do teatrólogo e pedagogo brasileiro Augusto Boal, cujo método conheci durante meus estudos universitários de teatro. Inicialmente eu me coloquei à disposição como consultora e captei as primeiras doações para financiamento do início do projeto. ${ }^{1}$ Geralda já tinha bastante experiência com trabalho prático de teatro com crianças e, além disso, ela própria escreve peças de teatro e crônicas. Quando ela constituiu o grupo em Serra Negra, imediatamente se juntaram vinte crianças e adolescentes de 3 a 15 anos.

Logo após o começo do projeto, Marion Küster deu seu apoio espontaneamente e começou a participar. Marion Küster leciona encenação e jogos de representação na Faculdade de Música e Teatro de Rostock (HMT) e tem longa experiência com teatro participativo e orientado a processos. Ela decidiu, com o engajamento dos seus alunos, a colaborar na construção do projeto.

1 Hoje o projeto em Serra Negra é financiado com recursos próprios, doações e com o apoio da Faculdade de Música e Teatro de Rostock e, recentemente, da Alice Salomon Hochschule de Berlim. Além disso, apóiam o trabalho a Fundação do Norte da Alemanha de Meio Ambiente e Desenvolvimento (Norddeutsche Stiftung für Umwelt und Entwicklung - NUE), assim como a Fundação Pontes Norte-Sul (Stiftung Nord-Süd-Brücken). Fizemos contatos com possíveis apoiadores brasileiros, como a FUNEDI, em Divinópolis, bem como com a Universidade Federal de Ouro Preto - UFOP. Agradeço a todos os apoiadores de "primeira hora". 
Como o projeto se desenvolveu desde então? O núcleo do projeto é o ensaio de teatro semanal com aproximadamente dez a 25 crianças e adolescentes da localidade. Hoje, esse trabalho é coordenado por Taciana Araújo Soares, pedagoga infantil que reside na localidade e mãe de crianças que participam do grupo de teatro. Ela é assistida por quatro jovens já formados no Teatro de 'Luz que Anda'. Paralelamente surgiu um time de futebol, que é treinado por seu marido, Dorinato, que é trabalhador rural. Uma pequena biblioteca deverá ser criada com doações de livros da biblioteca da cidade próxima. Evani Gonzalves da Rocha, uma outra mãe de crianças no teatro, se prontificou a ajudar a montar a biblioteca. Há interesse em um grupo de trabalhos manuais, coordenado por Geralda Celis Mendonça, uma moradora de Serra Negra vinda há alguns anos de São Paulo. Esse grupo de artesanato poderia ser uma oportunidade, especialmente para as mulheres da localidade que querem obter uma renda adicional. E uma funcionária do posto médico que mora no distrito, Tânia Aparecida Araújo Santos, quer organizar palestras sobre questões de saúde e educação em cooperação com a Universidade em Divinópolis. Esses são apenas alguns exemplos de idéias e iniciativas que surgiram da parte dos moradores no âmbito do projeto Luz que Anda.

O grupo de teatro criou diversas oportunidades para apresentar peças escritas por ele próprio ou por autores locais, como no Natal, Páscoa, festas tradicionais. Fizeram ainda teatro de rua e Teatro Fórum (um teatro político, que acontece com a participação do público). Adultos sempre participam também. Nós conduzimos na localidade entrevistas ativas para descobrir quais são as demandas da população, se o trabalho de teatro e a visita do grupo de apoio da Alemanha são bem-vindos, quais expectativas as pessoas ali possuem e até que ponto estão dispostos a participar do trabalho. Nós conduzimos, também, entrevistas sobre história da vida afim de aprender mais sobre a história e as condições de vida na localidade, e cujos resultados são acolhidos no trabalho do teatro. Além disso, foram organizadas assembléias regulares nas quais, por meio de trabalhos cênicos e pequenos exercícios, foram levantados os interesses da população do distrito e como ela pode se mobilizar. No verão de 2006 foi organizado um grupo de ativistas locais que apóia o trabalho do teatro e a cooperação com a iniciativa alemã. Foi fundada ali uma associação dos moradores da Serra Negra. O objetivo, segundo eles próprios, é primeiro a construção da praça do distrito e depois fazer com que um prédio de uma antiga escola na praça seja transformado em 
um centro de convivência com múltiplos usos. Além disso, muitos moradores querem que nas próximas eleições a comunidade de Serra Negra possa eleger um vereador para que seus interesses sejam representados em nível regional. Nesse período, portanto, o trabalho de teatro se transformou em um trabalho em toda a área social. As cidadãs e cidadãos formularam alguns objetivos para si e para sua comunidade. O trabalho do projeto Luz que Anda já se tornou conhecido em toda a região e conduziu a uma valorização do lugar e das crianças perante a população e perante os líderes políticos, os responsáveis pela educação e a igreja.

Da parte alemã, já se estabeleceu um ritmo semestral de estadias para o trabalho de campo, com a participação de estudantes e de orientadores. Além disso, em 2005 uma participante do projeto de origem teuto-curda, Derya Merdal, trabalhou com Geralda Araújo no distrito durante seis meses. A seguir irei detalhar como estão relacionadas nossas abordagens do teatro participativo e da pesquisa etnográfica da práxis. Ficará claro que ambas perseguem objetivos similares e que são regidas por princípios bastante semelhantes.

\section{Sobre o vínculo conceitual entre teatro participativo e pesquisa etnográfica da práxis}

\section{Objetivos e princípios do trabalho de teatro participativo}

O trabalho de teatro, como ele ocorre em Serra Negra, pode ser descrito com diferentes atributos: teatro sócio-espacial ou orientado ao mundo da vida, teatro político, teatro participativo, teatro engajado, mas ele também é, em parte, teatro popular. No centro não está tanto o teatro tradicional, voltado para a apresentação baseada em literatura clássica. Ao contrário, trata-se muito mais, tanto no palco quanto no dia-a-dia, de "observar nós mesmos em ação", como descrito por Augusto Boal: "Sou capaz de falar e de ouvir minha voz, entender meus pensamentos, observar meus gestos e controlar minhas ações. Isso é o que o ator faz” (Boal, 1996, p. 47). Aqui existe um paralelo com o cotidiano, pois mesmo enquanto pessoas comuns temos em princípio a possibilidade de ter acesso às nossas ações a distância, de nos observarmos. A esse respeito Boal ainda afirma que: “... mesmo se não fazemos teatro, nós 
somos teatro" (Boal, 1996, p. 47). Boal pensa que por meio do trabalho de teatro treina-se uma capacidade de percepção necessária, também, no dia-adia e, com isso, a capacidade para a transformação do desenvolvimento de padrões de ações inibidoras. De maneira semelhante afirma Erving Goffman (1959/69) em Nós todos fazemos teatro, que o mundo social é um palco. Ele recomenda aos cientistas sociais a tarefa de observar e decifrar essa representação de papéis do cotidiano. Boal, ao contrário, quer tornar as pessoas comuns capazes de observar a si mesmas e o mundo social por conta própria, romper com a fixação em modelos de pensamento e ação rotineiros, experimentar novas formas de vida e delas tirar consequiências para uma transformação emancipatória da própria forma de viver. Desta maneira, teatro participativo e socialmente orientado sempre é, também, pesquisa de mundos da vida, de suas possibilidades e seus limites estruturais imanentes.

O “Teatro do Oprimido", como Boal o desenvolveu sob as condições da ditadura militar no Brasil e, posteriormente, no exílio europeu, inspirado em Bertolt Brecht, no circo brasileiro e na Pedagogia do Oprimido de Paulo Freire, não tem qualquer objetivo pré-definido relativamente ao conteúdo. É um caminho, um processo. Em última análise, é um sistema de exercícios, jogos, técnicas, com o objetivo de ajudar todos os participantes, sejam eles atores, atores amadores ou público, a desenvolver a linguagem; poderíamos dizer também: a desenvolver o potencial que eles já trazem consigo.

Dessa maneira, este tipo de teatro é baseado na experiência, uma vez que ele capta aquilo que os participantes enfrentam no dia-a-dia ou o que eles fazem; ele é reconstrutivo, pois procura decompor experiências e observações em suas partes constitutivas - não por meio da linguagem em primeiro plano, mas por meio de jogos tentativos - e recompô-las novamente de modo estilizado. No jogo todos podem encontrar expressões para sua própria situação que não são apreendidas pela fala (situação corporal, sentimentos, atitudes difusas ou contraditórias). Aprende-se a destilar o que é típico das interações sociais (gestos, hábitos) e a desenvolver fantasias a partir de fragmentos da memória das próprias experiências, como descreveu Stanislawski com o conceito da "memória emocional". ${ }^{2}$ Além disso, o trabalho de teatro Luz que

2 Stanislawski, que, diferentemente de Boal, não fez teatro participativo, manteve a separação entre palco e público, possui a mesma opinião de Proust, de que se pode alcançar estado de excitação por meio de impressões externas. $\mathrm{O}$ ator compõe seu papel não mais por meio de 
Anda é interativo e participativo, na medida em que conteúdos, roteiro e papéis freqüentemente são elaborados em conjunto durante o ensaio ou desenvolvidos nos jogos. Para além disso, trabalhamos até agora muito com teatro de estátua, tanto com as crianças quanto com os adultos. ${ }^{3}$ Aqui, os participantes formam juntos, com seus corpos, imagens vivas que mostram como eles vivenciam a realidade social enquanto grupo. Trabalhamos dessa maneira por exemplo sobre o tema "escola" ou o tema "Serra Negra: ontem, hoje e amanhã”. Para a composição da imagem os participantes podem expressar suas associações ou encontrar títulos que expressam o que eles vêem. Pode-se também produzir uma série de imagens que explicitam a evolução de uma estrutura ou a possibilidade de mudar uma situação social.

Uma outra maneira do trabalho de teatro em Serra Negra inspirado em Boal é, por exemplo, a apresentação de peças próprias sobre temas da comunidade, à maneira do Teatro Fórum. Aqui não existe qualquer separação tradicional entre palco e público. Após a representação de uma cena, os espectadores são convidados a subir no placo com uma idéia. Eles próprios representam possibilidades de como a cena poderia se desenrolar, de maneira que o conflito seja resolvido ou que "o oprimido/a vítima" saia de seu papel de vítima, se torne consciente do que ele/ela próprio(a) faz para ser dependente. Boal critica o teatro tradicional, em que o ator enquanto sujeito ativo produz verdades aparentes e o espectador consome enquanto objeto passivo. Ele parte do pressuposto de que todo monólogo é opressor, inclusive aquele no teatro. Assistir significa, para Boal, estar excluído da ação, o oposto de participação (Baumann, 2001, p. 7s). Esta relação antidialógica "ocorre nas mais diferentes relações entre pessoas: entre professores e alunos, pais e filhos, em parcerias, institucionalizada nas estruturas de comando de um exército" (idem) e ritualizado especialmente também no teatro tradicional.

Dessa maneira, teatro participativo é, também, um trabalho criativo, orientado para soluções. O objetivo é integrar o conhecimento do jogo na própria vida, ou seja, pelo menos experimentar como outras estratégias dife-

inspiração casual, mas através do despertar de emoções. De maneira ideal, ele pode evocar esses sentimentos e emoções da memória da própria experiência de vida (Hentschel et al., 1997: 36). Na abordagem teatral, introduzida por Marion Küster no trabalho em Serra Negra, isso significa que os atores leigos no palco e do público são encorajados a trazer para o palco também sentimentos mais pessoais e sua experiência de vida.

3 Teatro Estátua também é uma forma do Teatro do Oprimido (Letsch e Balby, 2006: 18). 
rentes daquelas utilizadas até agora, podem funcionar com o objetivo de chegar a uma solução para um conflito, uma disputa, uma situação de poder, um problema social, etc. Em grande medida, desperta-se assim o desejo de transpor para a realidade o que se reconheceu e vivenciou no exercício. No Teatro Participativo trata-se exatamente de transformar a práxis social e, sobretudo, de transformar as condições de vida consideradas como obstáculos ao seu próprio desenvolvimento.

Um exemplo: na primeira estadia conjunta com Marion Küster em Serra Negra, Geralda Araújo nos deixou claro que o ônibus escolar conduz as crianças à escola, em São Sebastião do Oeste, a cerca de 15 km de distância, de forma muito irregular. Com freqüência ocorre das crianças estarem às 6 horas na parada e o ônibus chegar muito tarde ou simplesmente não vir porque estragou devido às más condições da estrada. Freqüentemente os pais são informados sobre o que aconteceu apenas ao meio-dia. As crianças que esperaram ficam decepcionadas e voltam para casa resignadas. Pouco a pouco elas perdem a motivação de ir à escola. Fizemos entrevistas com as crianças, perguntamos sobre a situação da escola. Ficamos sabendo, assim, que elas, na escola, como crianças do meio rural, se sentem desprivilegiadas, excluídas e desacreditadas pelos professores. Após sucessivas faltas do ônibus esse tema foi abordado por Marion Küster e Geralda Araújo em uma aula de teatro. As crianças deveriam assumir com o corpo uma postura que expressasse como elas se sentiram acerca do que ocorreu na manhã em que o ônibus não veio. Cada criança formulou uma palavra que se adequasse ao sentido do ocorrido. Uma a uma as crianças foram substituídas pela coordenadora do exercício e puderam ver a própria atitude e a imagem do grupo e, novamente, encontrar uma palavra para a situação. As atitudes e palavras estavam marcadas por desânimo, resignação e raiva. Em seguida, as crianças trabalharam no exercício como seria um outro futuro e como se poderia obter comportamentos para isso. Ao final, as crianças receberam a tarefa de desenvolver uma cena sobre o que seus pais poderiam fazer nessa situação para se chegar a uma mudança. Este exercício revelou que, na fantasia e na experiência das crianças, os adultos reagiram apenas com passividade e desesperança. Depois disto, elas deveriam representar aquilo que elas próprias como crianças poderiam fazer. Assim, desenvolveu-se uma cena bastante animada em que foi escrita uma carta à diretora, que foi entregue a ela pelas crianças. Essa estratégia de ação, descoberta por conta própria, entusiasmou tanto as crianças que elas decidiram 
de fato escrever tal carta. A carta foi entregue; a direção da escola percebeu que havia um conhecimento mais amplo do problema. Desde então o projeto "Luz que Anda" de Serra Negra ficou reconhecido também na escola; a direção convidou as crianças a apresentar uma peça na escola. Durante duas estadias de estudantes da Alemanha em Serra Negra ocorreu um curso de capacitação de coordenador de teatro para os professores. Sob a coordenação de Geralda Araújo e de nossa estagiária, Derya Merdal, as crianças desenvolveram elas próprias peças de teatro, dentre elas uma com o tema "O dia em que o ônibus não veio". Elas apresentaram a peça na localidade e o público adulto foi convidado a encontrar soluções e encerrar o final da peça de uma outra maneira. A participação foi tímida, mas ao final ficou decidido convocar uma reunião pública para discutir os problemas do ônibus escolar e do lixo. Ali ficou decidido apresentar esses problemas ao prefeito do município. Agora é voz corrente na localidade que, desde então, o transporte funciona melhor e as crianças encontram mais respeito na escola. Isso é apenas um exemplo. Muitos outros temas, por exemplo como lidar com o lixo, como lidar com pessoas com deficiência, a situação dos trabalhadores rurais no distrito, a experiência com violência na família e maternidade na adolescência se tornaram temas no projeto e no seu entorno. Todos esses temas de uma maneira ou outra foram levados ao palco e, em parte, apontados até mesmo na igreja. O Padre é constantemente informado sobre o projeto e ele dá um grande apoio ao trabalho. Participam, sobretudo, a população do distrito, mas nesse ínterim vêm também espectadores dos distritos vizinhos assistir às apresentações de teatro.

Tal processo possui muitos efeitos paralelos: a vivência e expressão no teatro faz com que os participantes estejam em contato com as próprias possibilidades e recursos e, assim, podem sentir prazer na própria criatividade. Nas encenações eles aprendem a perceber o corpo, o espírito, a alma e sentidos em sua articulação. Eles exercitam a concentração, treinam movimento e voz, capacidade de observação e fantasia. Eles eliminam estresse e inibição. Eles apreendem fenômenos normalmente ocultos, como sentimentos, o impacto de suas próprias ações ou, ainda, fronteiras estruturais em seu meio social, que freqüentemente lhes são inacessíveis pela linguagem falada. Eles aprendem a interessar-se pelos parceiros. Eles vivenciam o valor de um grupo e têm a experiência que a confiança é possível e como se constrói confiança. 


\section{Objetivos e princípios da pesquisa etnográfica da práxis}

Penso que ficou claro que esse projeto se caracteriza por uma dinâmica complexa, que se encontra em diversos níveis que não se pode apreender nem são visíveis quando se está envolvido. Isso se deve, dentre outras coisas, ao fato de não haver um arcabouço institucional; está relacionado a um desejado alto potencial de criatividade e espontaneidade. Está relacionado também à comunicação transcultural, que provoca não apenas euforia, mas que é também acirrador da complexidade e, no bom sentido, do estranhamento e do embaraço. Assim como está relacionado à provocação deliberada de processos, cujo desfecho ninguém conhece. Com isso tenho em mente não apenas o processo externo, como os efeitos continuados dos exercícios do teatro ou de uma apresentação de teatro na localidade. Mas também processos internos, que ocorrem aparentemente em todos os participantes. Cada um encontra a dinâmica do projeto e os exercícios ou o jogo em uma fase de sua história de vida e, para cada um, ela possui um significado próprio. Com isso, faz sentido acompanhar o projeto com uma pesquisa da práxis. Essa pesquisa participante serve à própria reflexão, à de outros e à reflexão sobre a práxis. Suas percepções são utilizadas diretamente no desenvolvimento do projeto. Assim como no trabalho de teatro, a pesquisa da práxis tem por objetivo empregar tanto o processo de pesquisa quanto seus resultados preliminares e seus resultados finais na mudança de uma práxis. Pesquisa da práxis ou da ação implica que não existe uma separação rigorosa entre pesquisadores e atores no campo de ação. Isso implica num entrelaçamento especial com o campo de pesquisa, que precisa ser pensado. Observação participante e a análise do diário de campo podem aqui refinar metodicamente as possibilidades de reflexão cotidianas.

Por que os métodos da pesquisa etnográfica da práxis são adequados para acompanhar um projeto desse tipo? 1) Quando descrevi o trabalho de teatro como sendo baseado na experiência, reconstrutivo e interativo, isso é válido também para os métodos interpretativos de etnografia e biografia, que são aqui adotados. Pois a pesquisa social reconstrutiva está interessada nas experiências e construções cotidianas das pessoas. Através delas se busca conhecer as estruturas sociais nas quais vivemos. O método é reconstrutivo porque não deriva conclusões de pressupostos teóricos, que depois devem interpretar fatos empíricos. Mas porque a partir de material empírico ou de 
fatos, ou seja, de textos coletados, pouco a pouco é elucidada a estrutura interna de processos de ação e de interpretação. Ele é interativo uma vez que sem comunicação nenhum material pode ser coletado: tanto em entrevista quanto na discussão de grupo ou na observação participante estamos inseridos como pesquisadores e estamos, por isso, envolvidos na construção do material. Os adjetivos participativo e orientado para a solução dizem respeito à postura fundamental de uma pesquisa participativa, que, de maneira consciente, incorpora leigos enquanto atores no processo de pesquisa. Na pesquisa participativa trata-se menos de produzir resultados específicos para questões de pesquisa, mas trata-se sobretudo de documentar a mudança das formas de ver e comportar-se daqueles atores envolvidos no processo (Rifkin, 2002, p. 177). A pesquisa da práxis também tem como objetivo - assim como o trabalho de teatro - empregar o processo de trabalho, bem como seu resultado, na transformação de relações sociais que impedem o desenvolvimento das pessoas. 2) A abordagem pedagógica do teatro e a abordagem da pesquisa social etnográfica se articulam de uma outra maneira: porque para ambas a observação e a percepção da realidade social cotidiana são um ponto de partida. É uma base para o conhecimento e sua representação comunicativa. O exercício de alternância de compreender-representar-compreenderrepresentar é realizado por ambas abordagens, certamente às vezes com peso e seqüência distintas: enquanto que a tendência no teatro seja primeiro representar e depois compreender, na pesquisa social é o inverso. 3) Tanto no teatro quanto na pesquisa trata-se de reconstruir as características generalizáveis de um fenômeno especial e torná-las públicas. 4) A pedagogia do teatro compartilha com a abordagem da pesquisa social etnográfica também a atenção e o olhar interrogante sobre os processos entrecruzados de ações e interpretações. 5) Tanto no jogo de teatro quanto na reconstrução das ciências sociais são testadas alternativas de ação. No teatro participativo, alternativas de ação são testadas in praxi. Na análise reconstrutiva de textos, alternativas de ação são delineadas hipoteticamente como formas de leitura, a fim de se obter a estrutura e a característica de um caso específico. Existem, portanto, em muitos aspectos, conexões produtivas.

Os métodos: entrevistas qualitativas de todo tipo, narrativas em grupo, observação participante (Riemann, 2004) e análise de fotos e vídeos podem ser empregados com finalidades distintas, seguramente para os objetivos de documentação e levantamento de temas da localidade. Desta maneira Geralda 
Araújo realizou entrevistas com os moradores da localidade com o objetivo de saber quais são os temas relevantes para eles. Comecei a levantar as biografias dos moradores da localidade que, com o tempo, poderão compor um arquivo da localidade e de sua história. Para esse trabalho irei ainda instruir moradores para que eles próprios possam aprender a documentar sua própria história. Por um lado, entrevistas narrativas de biografia (Schütze, 1987) são úteis para conhecer melhor a história do lugar e seus moradores. Por outro lado, toda entrevista biográfica fortalece a pessoa entrevistada. Quando alguém tem tempo e espaço de contar sobre si mesmo, isso incentiva a autocompreensão da própria pessoa e a capacidade de recordar e falar sobre si mesmo. Essas são competências de grande importância em uma sociedade moderna. Alguém que pode falar sobre sua própria biografia aprende a conhecer a si mesmo, seu passado e seus desejos para o futuro. Pode-se, assim, ter acesso a si mesmos à distância e descobrir possibilidades para a melhoria da condução da própria vida. Pode-se apresentar melhor sua pessoa (por exemplo em uma entrevista de emprego) e ganhar auto-confiança para apresentar de maneira efetiva as próprias vontades diante de outras pessoas e de outros interesses.

Em segundo lugar, adotamos os métodos para o acompanhamento e avaliação do processo no local. Nós, por exemplo, perguntamos aos atores brasileiros do projeto "Luz que Anda", ao final de cada estadia, como eles vivenciaram o trabalho, do que eles gostaram e o que eles gostariam de modificar.

Em terceiro lugar, os métodos reconstrutivos ajudam os envolvidos a refletir sobre a interação e a dinâmica do grupo: assim que conduzi narrativas em grupo com os estudantes alemães que viajaram ao Brasil, uma antes e outra após a viagem. A questão inicial que propus - narrar em conjunto a história desde o planejamento, a viagem, a chegada, o tempo na localidade até a saída de Serra Negra - provoca uma narrativa e uma discussão na qual os elementos das narrativas individuais, a partir da perspectiva de cada um, se entrelaçaram em um processo de grupo.

Por exemplo, uma das narrativas em grupo teve seu ponto mais alto após a viagem, com o tema de "Medo do desconhecido", preconceito e estranhamento no contato com outras culturas. Interessante foi que apesar disso foi afirmado, de maneira explícita, por vários participantes, que eles não descobriram nada surpreendente ou novo no Brasil. Em primeiro plano estava, ao 
contrário, a insegurança e estranhamento que eles tiveram no contato com a direção (até aquele momento bem conhecida) do grupo. Dito de outra maneira, o estranho tornou-se conhecido do grupo em um lugar estranho, e conseqüentemente tornou-se normal. E o conhecido tornou-se estranho, vivenciado e reconstruído de maneira surpreendente. Assim, é possível, no longo prazo e com tempo suficiente, iniciar processos de autocompreensão e reflexão.

Em quarto lugar, os métodos utilizados permitiram aos pesquisadores aprender. Por exemplo, durante um seminário reconstruímos em conjunto um pequeno trecho do diário de campo de uma estudante. Tratava-se de uma aula de teatro em Serra Negra, que foi acompanhada por batidas na porta por jovens do lugar que estavam do lado de fora da sala. Aqui pudemos obter uma visão sobre a organização do trabalho, a divisão do trabalho e dos papéis dentro do grupo de estudantes, visões características estruturais do trabalho de teatro, bem como sobre a dinâmica entre as crianças e adolescentes do local, entre as meninas e meninos em relação ao trabalho de teatro. Com essa passagem refletimos conjuntamente variantes de um procedimento alternativo em uma tal situação. No exercício de papéis modificamos as cenas descritas no diário de campo ainda de uma outra maneira (Völter/Küster, no prelo). Com isso surge uma outra compreensão da situação sobre as possíveis alternativas futuras. Essas variantes puderam ser concebidas livres de pressão por ação e estão à disposição dos estudantes e à nossa disposição enquanto coordenação, quando novamente estivermos confrontados com uma situação semelhante.

Pesquisa participante, que também capacita ou inclui cientistas sociais leigos no projeto como pesquisadores, traz consigo duas dificuldades: por um lado, temos que em parte - pelo menos no início - darmo-nos por satisfeitos com um material bastante rudimentar comparado àquele que pesquisadores sociais profissionais poderiam produzir. Por outro lado, há o perigo de fusão de papéis: a pesquisadora têm que se movimentar entre a exigência de agir como participante e coordenadora do projeto e a exigência de manter a distância necessária em relação aos acontecimentos. E ela se movimenta no dilema entre dois sistemas de referência: de um lado, ela se sente comprometida com o sistema de referência científico, com suas formas de procedimento, linguagem etc., e, de fato, ela deve estar comprometida com ele para que seu trabalho possa ser considerado. Por outro lado, ela estará confrontada ao mesmo tempo com o sistema de relevância da práxis. Ela não pode satisfazer 
completamente a todas as exigências, mas somente fornecer estímulos recíprocas para novas possibilidades de pensamento. Ela se encontra sobre "um cabo de guerra individual enquanto caminhante entre dois mundos”, como Ulrike Höhmann o descreve (Höhmann, 2002, p. 196). Poder-se-ia dizer também que ela se equilibra entre duas culturas de conhecimento. É essencial realizar esforços de tradução de uma linguagem teórica para uma linguagem do dia-a-dia, uma boa medida de distanciamento de papéis, atividade de reflexão e tolerância com a ambigüidade, o que nem sempre é fácil desenvolver e manter.

\section{Potencialidades e questões suscitadas no trabalho transcultural}

Chego à terceira e última seção e questiono sobre as potencialidades e questões no trabalho transcultural de "Luz que Anda”. As potencialidades são evidentes. Trata-se de aprender como na ação lúdica surgem motivações, como potenciais podem ser encorajados e transformações iniciadas. Com isso os participantes da Alemanha e do Brasil aprendem uns dos outros, uns com os outros e por intermédio uns dos outros as construções do familiar e do estranho.

Sobre as questões: entendemos o projeto conscientemente enquanto uma cooperação, distinto por exemplo de ajuda para o desenvolvimento. É evidente que ajuda constrói dependências e com isso hierarquia e relações de poder. Os obstáculos são, contudo, as diferenças de formação entre participantes alemães e brasileiros do projeto - definidas como tais na perspectiva oficial e experimentadas por todos como diferença de habitus-, que influenciam sobretudo porque existem experiências biográficas profundas com a exclusão do sistema educacional brasileiro. Naturalmente ocorrem no projeto, também, imputações culturais e sociais recíprocas. A mais evidente é a distinção subliminar e efetiva entre "Primeiro e Terceiro Mundo". A isso vinculam-se experiências de socialização de opressão, exclusão, privação e de estratégias de desamparo e lamúria, desenvolvidas sobre essas bases. Por outro lado, existe a consciência pesada, o desejo de construir sentido por meio da ajuda, receber reconhecimento, a esperança de encontrar o exótico em um país estrangeiro, de vivenciar a sensualidade da cultura brasileira, a generosidade e proximidade por meio do estranhamento. 
Estamos convencidos de que não faz sentido continuar a seguir de maneira irrefletida esta forma de pensamento e ação perigosa e sedutora para todas as partes, assim como aparentemente fácil. Um outro esforço sempre necessário no projeto é desenvolver um novo olhar para as circunstâncias, descrevê-las sempre de novo - no sentido de uma parceria cooperativa. Nesse sentido considero problemático falar em "intervenção" quando se trata de teatro na comunidade. Pois descrevemos imediatamente de novo uma hierarquia: de um lado, aqueles que têm o poder e os meios para intervir, mas que não precisam modificar-se; de outro lado, aqueles que necessitam do empoderamento e que são objeto da intervenção, porque precisam do desenvolvimento. Nós compreendemos e vivenciamos o projeto de teatro, ao contrário, como aquele que obriga a todos os participantes à autotransformação e à auto-relativização, que pressupõe que todos aprendam algo sobre si no intercâmbio transcultural e que estejam dispostos a suportar a experiência da diferença dentro e entre as culturas e utilizá-la de maneira produtiva.

O projeto tem a oportunidade de tornar isso experienciável também no jogo: por exemplo, através da construção de estátuas para nossas expectativas recíprocas. Em um tal processo vivenciado em conjunto aparece também claro, mesmo sem palavras, quais subtextos implícitos acompanham nossas ações. Pois, a partir da representação, realidades sociais são definidas e construídas. Nossas palavras possuem efeitos de longo prazo para nossa ação, para nossas relações comunicativas, para nossa visão sobre o mundo social.

Uma outra dúvida que pode acompanhar um tal projeto é se de fato podemos fazer o que nós fazemos. Que direito temos afinal para intervir, especialmente em um outro país, com uma forma de vida e de perspectiva de vida totalmente diferentes? Temos algum mandato ou não seria até mesmo arrogância querer se envolver? Por esse motivo também é importante avaliar o projeto. Com isso pode-se sempre verificar se há uma legitimação e qual efeito tem o trabalho.

No Brasil existe um ritual que é símbolo do pertencimento para brasileiros negros de algumas regiões convertidos ao cristianismo. A Igreja excluiu, freqüentemente, dos seus ritos e de seus ambientes os negros batizados e faz isso, em parte, hoje ainda. Por esta razão os grupos de Congado saem sempre de dentro, ou do Portal da igreja, para deslocar-se pelas ruas do povoado e terminam novamente diante da igreja, ou no interior da igreja. Eles simboli- 
zam a resistência contra os brancos e se compreendem como uma demonstração de coragem e dignidade. O Congado é um ritual de dança, que é acompanhado por cantos e ritmos. Lembra, de um lado, o sofrimento de Cristo e o sofrimento, sob a escravidão, dos antepassados trazidos da África. A lenda diz que Nossa Senhora do Rosário, que é conduzida em um estandarte diante do grupo e que é admirada pelo público, apareceu para escravos negros e ficou com eles. E ela fala de Chico-Rei, que unificou com sucesso os escravos no lugar onde hoje é Ouro Preto, e que se tornou Rei posteriormente. Também hoje nos rituais praticados existe um "rei”, um protagonista que no mito dança e canta seu grupo de Congado. Ele é escolhido pela comunidade para isso. Em Serra Negra este protagonista é José Bernardes dos Santos, cujo apelido é Zé da Marieta. Ele é um dos homens mais ativos do lugar. O grupo de Congado ensaia durante todo o ano para se apresentar nas grandes festas da região, quando todos os grupos de Congado se encontram. Durante quase todas as nossas visitas e durante algumas apresentações do projeto Luz que Anda, o grupo de congado de Serra Negra também se apresentou. O grupo foi e voltou da igreja ao lugar onde atuavam os participantes do projeto. Lá, cada um dos membros do projeto foi cantado e abençoado por Zé da Marieta, acompanhado pela população. Cada um do grupo alemão do projeto vivenciou isso como uma grande honra.

A partir do distanciamento analítico pudemos refletir sobre as seguintes questões: como o antropólogo Victor Turner, que viu os rituais como expressão de conflitos cotidianos mundanos, não articulados e não passíveis de resolução na comunidade, pudemos refletir sobre o significado do ritual em relação ao projeto no local. Visto superficialmente: bem-vindos, despedida, convite para retornar. E, visto de maneira mais detida, talvez pode ser também uma combinação de orgulho da própria cultura, que não precisa ser importada primeiro pelos “alemães brancos”; de estranhamento, que precisa ser superado no ritual, porque, do contrário, cria-se uma grande distância entre os atores e que, por sua vez, se manifesta; de reconhecimento humano, respeito, agradecimento e questionamento, que retroalimenta a comunicação entre os participantes e apoiadores alemães e brasileiros. 


\section{Referências}

BAUMANN, Till. Von der Politisierung des Theaters zur Theatralisierung der Politik. Theater der Unterdrückten im Rio de Janeiro der 90er Jahre. Stuttgart: ibidem-Verlag, 2001.

BOAL, Augusto. Politics, Education and Change. In: O’TOOLE, J.; DONELAN, K. (ed.). Drama, Culture and Empowerment. The IDEA Dialogues. Brisbane: IDEA Publications, 1996, p. 47-52.

GOFFMAN, Erving. Wir alle spielen Theater. Die Selbstdarstellung im Alltag. München: Piper, 1959/1969.

HENTSCHEL, Ingrid; HOFFMANN, Klaus; VAßEN, Florian (org.). Brecht und Stanislawski und die Folgen. Berlin: Henschel Verlag, 1997.

HÖHMANN, Ulrike. Kooperative Qualitätsentwicklung als Gegenstand partizipativer Interventionsforschung. In: SCHAEFFER, Doris; MÜLLER-MUNDT, Gabriele (orgs.). Qualitative Gesundheits- und Pflegeforschung. Bern/Göttingen/Toronto/ Seattle: Hans Huber Verlag, 2002, p. 179-200.

LETSCH, Fritz; BALBY, Vivi. Wie alles anfing. In: ODIERNA, S.; LETSCH, F. (org.). Theater macht Politik. Forumtheater nach Augusto Boal. Ein Werkstattbuch. Gautinger Protokolle 36 - Institut für Jugendarbeit Gauting. Neu-Ulm: AG SPAK Bücher, 2006, p. 14-21.

RIEMANN, Gerhard (2004): Die Befremdung der eigenen Praxis. In: HANSES, A. (org.). Biographie und Soziale Arbeit. Hohengehren: Schneider Verlag, 2004, p. 190208.

RIFKIN, Susan, B. Partizipative Interventionsforschung - Prinzipien und Strategien. In: SCHAEFFER, Doris; MÜLLER-MUNDT, Gabriele (orgs.). Qualitative Gesundheits- und Pflegeforschung. Bern/Göttingen/Toronto/Seattle: Hans Huber Verlag, 2002, p. 167-178.

SCHÜTZE, F. Das narrative Interview in Interaktionsfeldstudien I. Studienbrief der FernUniversität Hagen. Kurseinheit 1. Fachb. Erziehungs-, Sozial- und Geisteswissenschaften, 1987.

VÖLTER, Bettina; KÜSTER, Marion. Ethnographische Praxisprotokolle und Rollenspiel. Eine Methode zur Projektreflexion in der interkulturellen und sozialräumlich orientierten Gemeindearbeit. Erscheint in: THOLE, W.; HEINZEL, F.; CLOOS, P.; KÖNGETER, S. (orgs.): Auf unsicherem Terrain. Ethnographische Forschung im Kontext des Bildungs- und Sozialwesens. Wiesbaden: VS-Verlag (no prelo). 